\title{
Impact of anatomic characteristics and initial biventricular surgical strategy on outcomes in various forms of double-outlet right ventricle
}

\author{
Olivier Villemain, MD, ${ }^{\mathrm{a}}$ Emre Belli, MD, ${ }^{\mathrm{b}}$ Magalie Ladouceur, MD, ${ }^{\mathrm{a}}$ Lucile Houyel, MD, \\ Zakaria Jalal, MD, ${ }^{\mathrm{a}}$ Virginie Lambert, MD, PhD, ${ }^{\mathrm{c}}$ Mohamed Ly, MD, ${ }^{\mathrm{b}}$ Pascal Vouhé, MD, PhD, and \\ Damien Bonnet, $\mathrm{MD}, \mathrm{PhD}^{\mathrm{a}}$
}

\begin{abstract}
Objectives: Surgical management of various forms of double-outlet right ventricle uses a variety of approaches depending on the underlying anatomic form. In this study, we sought to determine the risk factors of mortality and reoperation in those with double-outlet right ventricle undergoing biventricular repair, according to anatomic characteristics and initial surgical strategy.

Methods: Between 1992 and 2013, 433 patients were included in the study. Double-outlet right ventricle was classified as double-outlet right ventricle with subaortic ventricular septal defect associated with subpulmonary obstruction in $33 \%$ of patients $(\mathrm{n}=141)$, with subaortic ventricular septal defect without subpulmonary obstruction in $30 \%$ of patients $(n=130)$, with subpulmonary ventricular septal defect in $32 \%$ of patients $(\mathrm{n}=139)$, and with noncommitted ventricular septal defect in $5 \%$ of patients $(n=23)$. Three types of repairs were performed: (1) intraventricular baffle repair, $\mathrm{n}=149$ (34\%); (2) intraventricular baffle repair with right ventricular outflow tract reconstruction, $\mathrm{n}=163$ $(38 \%)$; and (3) intraventricular baffle repair with arterial switch operation, $\mathrm{n}=121(28 \%)$.
\end{abstract}

Results: Thirty-day overall mortality was $7.4 \%$. Early reoperation was needed in $6 \%$ of the cases. Early mortality was higher in the intraventricular baffle repair with arterial switch operation group $(P=.01)$. Survival at 10 years was $86.2 \%$, and freedom from reoperation at 10 years was $61.4 \%$. At last follow-up (median, 5.7 years; $95 \%$ confidence interval, $4.5-6.6$ ), mortality and reoperation rates were similar in the different surgical strategy groups. Late reoperation and late mortality were significantly higher in the double-outlet right ventricle with noncommitted ventricular septal defect group $(P<.01)$. In multivariate analyses, risk factors for reoperation were concomitant surgical procedures $(P=.03)$ and duration of cardiopulmonary bypass $(P<.01)$. Risk factors for mortality were restrictive ventricular septal defect $(P=.01)$, mitral cleft $(P<.01)$, and associated coronary artery anomalies $(P=.01)$.

Conclusions: Those with the anatomic type of double-outlet right ventricle with noncommitted ventricular septal defect were at higher risk for reoperation and mortality. Intraventricular baffle repair with arterial switch operation was the surgical strategy in patients at higher risk of early death. Initial surgical strategy did not influence the late outcomes. (J Thorac Cardiovasc Surg 2016;152:698-706)

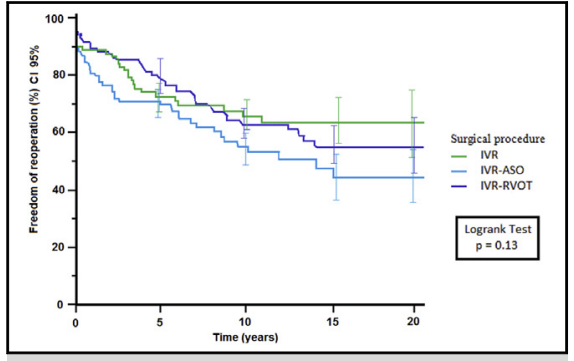

Freedom from reoperation according to surgical strategy.

\section{Central Message}

The initial surgical strategy did not influence late outcomes of DORV with biventricular repair.

\section{Perspective}

The outcomes of DORV with biventricular repair remain unclear. Between 1992 and 2013, 433 consecutive patients were retrospectively included. Early mortality was higher in the IVR-ASO group. Late mortality and late reoperation rates were similar in the different biventricular surgical strategy groups, but were significantly higher in DORV with ncVSD. Multiple risk factors have been identified.

See Editorial Commentary page 707.
From the ${ }^{\mathrm{a}} \mathrm{M} 3 \mathrm{C}-\mathrm{Necker}$ Enfants Malades, AP-HP, Université Paris Descartes, Sorbonne Paris Cité, Paris, France; ${ }^{b}$ Centre Chirurgical Marie Lannelongue, M3C, Université Paris Sud, Le Plessis Robinson, France; and ${ }^{\mathrm{c} P e d i a t r i c ~ D e p a r t-~}$ ment, University Hospital of Bicetre, le Kremlin Bicetre, France.

Received for publication Dec 12, 2015; revisions received April 26, 2016; accepted for publication May 9, 2016; available ahead of print June 24, 2016.

\footnotetext{
Address for reprints: Olivier Villemain, MD, Hôpital Necker Enfants Malades, Cardiologie Pédiatrique, 149 rue de Sèvres, 75015 Paris Cedex, France (E-mail: olivier.villemain@inserm.fr). $0022-5223 / \$ 36.00$

Copyright (C) 2016 by The American Association for Thoracic Surgery http://dx.doi.org/10.1016/j.jtcvs.2016.05.019
} 


$$
\begin{aligned}
& \text { Abbreviations and Acronyms } \\
& \begin{aligned}
\text { ASO } & =\text { arterial switch operation } \\
\text { AV } & =\text { atrioventricular } \\
\text { AVSD } & =\text { atrioventricular septal defect } \\
\text { CI } & =\text { confidence interval } \\
\text { CPB } & =\text { cardiopulmonary bypass } \\
\text { DORV } & =\text { double-outlet right ventricle } \\
\text { IVR } & =\text { intraventricular baffle repair } \\
\text { ncVSD } & =\text { noncommitted ventricular septal defect } \\
\text { OR } & =\text { odds ratio } \\
\text { REV } & =\text { réparation à l'étage ventriculaire } \\
\text { RVOT } & =\text { right ventricular outflow tract } \\
\text { VSD } & =\text { ventricular septal defect }
\end{aligned}
\end{aligned}
$$

Scanning this QR code will take you a video and supplemental tables.

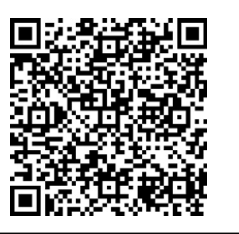

Double-outlet right ventricle (DORV) is a type of ventriculoarterial connection (or alignment) of the great arteries in which both great arteries arise entirely or predominantly from the right ventricle. ${ }^{1}$ DORV is a heterogeneous group of congenital heart diseases subclassified by the International Nomenclature Committee for Pediatric and Congenital Heart Disease, according to the relationship of the ventricular septal defect (VSD) to the great arteries and to the presence or absence of pulmonary outflow tract obstruction (International Pediatric and Congenital Cardiac Code). ${ }^{2}$

In 1964, Kirklin and colleagues ${ }^{3}$ reported a successful biventricular repair in a child with DORV, subaortic VSD, and concordant atrioventricular (AV) connections. Since then, complete correction through the use of a variety of surgical techniques has been achieved in more complex forms of DORV. The feasibility of a biventricular repair still remains a surgical challenge in the management of DORV. ${ }^{4,5}$ Previous series reported successful biventricular surgical repair in different anatomic subtypes of DORV. ${ }^{6-8}$ Thus far, however, 2 points still remain unclear: which surgical strategy implies a higher risk of mortality or reoperation and when to abandon the ambition of biventricular repair. In this study, we sought to determine the risk factors for mortality and reoperation in those with DORV undergoing biventricular repair according to anatomic characteristics and initial surgical strategy.

\section{MATERIALS AND METHODS \\ Patients}

We reviewed all records of consecutive patients with DORV who underwent operation in 2 French centers (Necker Enfants Malades, Paris,
France; Centre Chirurgical Marie Lannelongue, Le Plessis Robinson, France) between 1992 and 2013. Those with conotruncal anomalies with the presence of double conus but without both great arteries arising entirely or predominantly from the right ventricle ${ }^{9}$ were not included in this cohort. Those with DORV associated with double-inlet ventricle, absent AV connection, or severely imbalanced ventricles precluding biventricular repair were excluded. The diagnosis of DORV with 2 balanced ventricles (or mild asymmetry not precluding biventricular repair) was confirmed after review of echocardiograms, cardiac magnetic resonance imaging or computed tomography scans, angiograms, and surgical reports. In all cases, the type of DORV was finally confirmed according to the anatomic description given by the surgeon. When biventricular repair was considered unattainable in light of both preoperative investigations or intraoperative evaluation, the patient was excluded. Demographic data included gender, prenatal or postnatal diagnosis, center, and associated genetic anomalies.

Four anatomic groups were defined according to the classification of the International Pediatric and Congenital Cardiac Code' ${ }^{2}$ (1) subaortic or doubly committed VSD and subpulmonary obstruction, Fallot type; (2) subaortic or doubly committed VSD without subpulmonary obstruction, VSD type; (3) subpulmonary VSD, Taussig-Bing type ${ }^{10}$; and (4) noncommitted VSD (ncVSD) type.

Along with Lev and colleagues, ${ }^{11}$ we defined the VSD in DORV according to the direction of the blood flow coming from the left ventricle through the VSD: directly into the aorta (subaortic VSD), the pulmonary artery (subpulmonary VSD), or both (doubly committed VSD). These "committed" VSDs always open in the outlet of the right ventricle and are cradled within the limbs of the septal band (outlet VSD). Conversely, the blood flow through an ncVSD is not directed toward the outflow tract, but directly toward the right ventricular cavity, running perpendicular to the ventricular septum. We include in this category all the VSDs that are not located between the 2 limbs of the septal band, that is inlet, muscular, and central membranous VSD. ${ }^{12}$

Associated cardiac anomalies were noted: VSD (location, number, and restriction when significant pressure gradient between the ventricles was diagnosed), subpulmonary and subaortic obstruction, atrioventricular septal defect (AVSD), mitral valve cleft and other mitral valve anomalies, straddling of the mitral or of the tricuspid valve, and coronary artery anomalies.

Three surgical strategies were used: (1) intraventricular baffle repair (IVR); (2) IVR with right ventricular outflow tract (RVOT) reconstruction, including IVR with RVOT patch enlargement, réparation à l'étage ventriculaire (REV), and Rastelli procedures, IVR-RVOT; and (3) IVR with arterial switch operation (ASO), IVR-ASO.

Concomitant surgical procedures were reported: VSD enlargement, AV valve repair, correction of abnormal pulmonary venous return, coarctation or interrupted aortic arch repair, chordae mobilization, subaortic stenosis resection, and pulmonary artery branch stenosis repair.

Surgical data included prior palliative intervention, age and weight at time of repair, date of surgery, surgical strategy, concomitant surgical procedure, cardiopulmonary bypass (CPB) duration, duration of mechanical ventilation, reoperation, and delay between repair and reoperation.

Finally, we collected early mortality and reoperation occurring less than 30 days after repair and late mortality and reoperation occurring more than 30 days after repair. Follow-up information was available in 341 of 381 surviving patients $(90 \%)$. This study was approved by our ethics board (Comité de Protection des Personnes-Ile-de-France VI).

\section{Statistical Analysis}

Continuous variables are presented as the mean value \pm standard deviation when variables were normally distributed and median value with $95 \%$ confidence interval (CI) when they were not. Categoric variables are presented as percentages. Comparisons of categoric variables were made using the chi-square test or Fisher exact test when appropriate. 
Time to death and time to reoperation are shown in Kaplan-Meier curves and all actuarial curves start at the time of surgery. Cox proportional hazard regression analysis, with the date of repair used as the start date, was performed as univariate and multivariate analyses (Table E1 shows a list of variables considered for multivariable analyses) to investigate the risk factors for early death, late death, early reoperation, and late reoperation. When there were less than 10 outcome events per predictor variable, we used the chi-square or Mann-Whitney test to determine it as appropriate. We excluded early death and reoperation from the analysis when we evaluated late death or reoperation. All entered variables were selected on the basis of clinical experience, univariate analysis, and previously published data. Receiver operating curve analysis was used to study the ability of significant parameters to predict early death. Analysis was conducted using MedCalc (MedCalc Software, Mariakerke, Belgium).

\section{RESULTS}

\section{Population and Anatomic Characteristics}

Overall, we identified 482 patients with DORV. Eighteen patients had only a palliative procedure (death before biventricular repair) and were excluded. Thirty-one patients (6\%) followed a sequential cavopulmonary connection program and were excluded: 12 with DORV with ncVSD, 9 with multiple VSD, 5 with straddling mitral valves, and 5 with other severe mitral valve anomalies.

Finally, 433 DORV cases with 2 adequate ventricles underwent biventricular repair and were included in the study. Demographic and anatomic characteristics are summarized in Table 1. The surgical procedures are shown in the Video 1 (DORV with ncVSD with IVR-ASO).

The number and type of prior palliative interventions according to the anatomic groups are shown in Table 2. The 18 interventions listed in the group "Others" included 6 isolated pulmonary artery branch repair, 4 closures of the arterial duct, 3 partial cavopulmonary connections (converted secondarily to biventricular strategy), 2 corrections of partial anomalous pulmonary venous return, 1 tricuspid valve repair, 1 aberrant left pulmonary artery branch reimplantation, and 1 pacemaker implantation. The proportion of DORV with ncVSD requiring a palliative procedure before repair $(12 / 23,52 \%)$ was significantly higher than in the VSD type $(41 / 130,32 \% ; P<.01)$, Fallot type $(44 / 141,31 \% ; P<.01)$, and Taussig-Bing type $(38 / 139,27 \% ; P<.01)$. Table 3 shows the surgical strategy in the 4 anatomic groups with concomitant surgical procedures.

\section{Survival and Reoperation}

The median follow-up was 5.7 years $(95 \% \mathrm{CI}, 4.5-6.6)$. The overall survival was $87.8 \%$ at 1 year, $87.2 \%$ at 5 years, and $86.2 \%$ at 10 years. The overall freedom from reoperation rate was $86.5 \%$ at 1 year, $74.1 \%$ at 5 years, and $61.4 \%$ at 10 years. At last follow-up, 351 of 381 survivors $(92 \%)$ were in New York Heart Association functional class I, and 30 of 381 survivors $(8 \%)$ were in New York Heart Association functional class II.
TABLE 1. Patient characteristics

\begin{tabular}{|c|c|}
\hline Variable & No. $(\%)$ \\
\hline \multicolumn{2}{|l|}{ Demographic characteristics } \\
\hline Male/female & $260(60) / 173(40)$ \\
\hline Center (Necker/Plessis Robinson) & $216(50) / 217(50)$ \\
\hline Prenatal diagnosis & $171(39)$ \\
\hline Chromosomal/genetic abnormalities & $50(12)$ \\
\hline \multicolumn{2}{|l|}{ IPCCC classification } \\
\hline Fallot type & $141(33)$ \\
\hline VSD type & $130(30)$ \\
\hline Taussig-Bing type & $139(32)$ \\
\hline ncVSD type & $23(5)$ \\
\hline \multicolumn{2}{|l|}{ Anatomic characteristics } \\
\hline \multicolumn{2}{|l|}{ VSD } \\
\hline \multicolumn{2}{|l|}{ No. of VSDs } \\
\hline 1 & $373(86)$ \\
\hline Multiple & $61(14)$ \\
\hline Restrictive VSD & $35(8)$ \\
\hline \multicolumn{2}{|l|}{ Ventriculoarterial spatial relationship } \\
\hline D-malposition & $343(79)$ \\
\hline D side-by-side & $42(10)$ \\
\hline L-malposition & $24(5.5)$ \\
\hline L side-by-side & $2(0.5)$ \\
\hline Undetermined & $22(5)$ \\
\hline Subpulmonary obstruction & $184(42)$ \\
\hline Pulmonary atresia & $19(4)$ \\
\hline $\begin{array}{l}\text { Stenosis (infundibular/valvular/ } \\
\text { supravulvular) }\end{array}$ & $165(38)$ \\
\hline Subaortic and supra aortic obstructions & $101(23)$ \\
\hline Valvular or subvalvular aortic stenosis & $21(5)$ \\
\hline Coarctation of the aorta & $62(14)$ \\
\hline Interrupted aortic arch & $18(4)$ \\
\hline \multicolumn{2}{|l|}{ AV valve anomalies } \\
\hline AVSD & $12(3)$ \\
\hline Straddling & $67(16)$ \\
\hline Mitral/tricuspid/bivalvular & $17(4) / 42(10) / 8(2)$ \\
\hline Other mitral valve anomalies & $36(8)$ \\
\hline Coronary artery anomalies & $112(26)$ \\
\hline DORV Taussig-Bing type & $67 / 139(48)$ \\
\hline
\end{tabular}

$\overline{I P C C C}$, International Pediatric and Congenital Cardiac Code; VSD, ventricular septal defect; $n c V S D$, noncommitted ventricular septal defect; $A V$, atrioventricular; $A V S D$, atrioventricular septal defect; $D O R V$, double-outlet right ventricle.

Outcomes according to double-outlet right ventricle type. Those with noncommitted VSD had a higher risk of mortality $(P=.02)$ (Figure $1, A)$ and reoperation $(P=.04)$ (Figure $1, B$ ) in comparison with those with other anatomic types. Mortality was higher (hazard ratio, $2.18 ; 95 \% \mathrm{CI}$, $1.10-4.30$ ) and reoperation was more frequent (hazard ratio, $1.68 ; 95 \% \mathrm{CI}, 1.07-2.63$ ) in the Taussig-Bing type than in the VSD type. No difference was found in mortality or reoperation rate between the Taussig-Bing type and Fallot type, and between the VSD type and the Fallot type.

Outcomes according to surgical strategy. No significant statistical difference was found in late mortality $(P=.20)$ (Figure 2, $A)$ and late reoperation rate $(P=.13)$ (Figure 2,B) according to the 3 surgical strategies. 


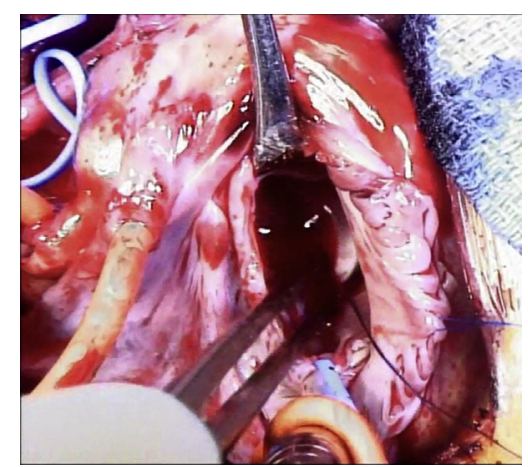

VIDEO 1. Example of IVR + ASO on a DORV with ncVSD + restrictive VSD. Video available at: http://www.jtcvsonline.org/article/S0022-5223(16) 30457-3/addons.

Early mortality. A total of 32 of 433 patients died within 30 days after repair $(7.4 \%)$. The causes of death were as follows: 12 during surgery (5 during IVR + ASO, with no significant statistical difference compared with the other surgical strategies; odds ratio [OR], 1.7; 95\% CI, 0.4-5.7; $P=.47), 4$ during IVR with concomitant surgical procedure (AV valve repairs and coarctation repairs), and 3 during IVR-RVOT with concomitant surgical procedures (AV valve repairs, correction of APVR, and subaortic stenosis resection); 7 sepsis cases, 4 low cardiac output syndromes, 4 pulmonary hypertension crises, 2 electromechanical dissociations, 1 hemorrhage, and 2 unclearly explained. Early postoperative characteristics are shown in Table 4. The IVR + ASO was the surgical strategy with the highest rate of early death $(\mathrm{OR}, 3.1 ; 95 \% \mathrm{CI}, 1.4-7.1 ; P=.01)$. The causes of early death after IVR + ASO (15 patients) were 5 during surgery, 4 sepsis cases, 2 low output cardiac failures, 1 pulmonary hypertension crisis, 1 electromechanical dissociation, 1 hemorrhage, and 1 unclearly explained. Early mortality was significantly higher in DORV with ncVSD $(P=.04)$, low weight at operation $(P=.04)$, left ventricular outflow tract obstruction $(P=.04)$, and associated surgical procedure $(P=.03)$. By using receiver operating characteristics, weight less than $4000 \mathrm{~g}$ predicted

TABLE 2. Prior palliative interventions according to anatomic groups (180 procedures in 135 patients [31\%])

\begin{tabular}{lrrcrr}
\hline & $\begin{array}{c}\text { Fallot } \\
\text { type }\end{array}$ & $\begin{array}{c}\text { VSD } \\
\text { type }\end{array}$ & $\begin{array}{c}\text { Taussig- } \\
\text { Bing type }\end{array}$ & $\begin{array}{c}\text { ncVSD } \\
\text { type }\end{array}$ & Total \\
\hline No. of patients & 44 & 41 & 38 & 12 & 135 \\
PA banding & 2 & 25 & 10 & 12 & 49 \\
PA banding + CoA repair & 0 & 16 & 10 & 1 & 27 \\
Blalock shunts & 42 & 0 & 14 & 15 & 71 \\
Atrial septectomy & 2 & 1 & 8 & 4 & 15 \\
Others & 6 & 2 & 6 & 4 & 18 \\
Total & 52 & 44 & 48 & 36 & 180 \\
\hline
\end{tabular}

$V S D$, Ventricular septal defect; $n c V S D$, noncommitted ventricular septal defect; $P A$, pulmonary artery; $C o A$, coarctation of the aorta.
TABLE 3. Surgical strategy according to anatomic group

\begin{tabular}{|c|c|c|c|c|c|}
\hline & $\begin{array}{c}\text { Fallot } \\
\text { type }\end{array}$ & $\begin{array}{l}\text { VSD } \\
\text { type }\end{array}$ & $\begin{array}{l}\text { Taussig- } \\
\text { Bing type }\end{array}$ & $\begin{array}{c}\text { ncVSD } \\
\text { type }\end{array}$ & Total \\
\hline IVR & 28 & 114 & 0 & 7 & 149 \\
\hline IVR-RVOT & 113 & 16 & 23 & 11 & 163 \\
\hline REV & 2 & 0 & 9 & 0 & 11 \\
\hline Rastelli & 11 & 1 & 12 & 5 & 29 \\
\hline IVR-ASO & 0 & 0 & 116 & 5 & 121 \\
\hline Total & 141 & 130 & 139 & 23 & 433 \\
\hline \multicolumn{6}{|l|}{ Concomitant surgical procedures } \\
\hline $\begin{array}{l}\text { Enlargements of restrictive } \\
\text { VSD }\end{array}$ & 11 & 15 & 0 & 9 & 35 \\
\hline Coarctation repairs & 0 & 13 & 16 & 3 & 32 \\
\hline $\mathrm{AV}$ valve repairs & 13 & 6 & 3 & 2 & 24 \\
\hline Subaortic stenosis resections & 2 & 6 & 5 & 3 & 16 \\
\hline APVR repairs & 2 & 2 & 0 & 2 & 6 \\
\hline $\begin{array}{l}\text { Pulmonary artery branch } \\
\text { plasties }\end{array}$ & 2 & 2 & 1 & 0 & 5 \\
\hline Chordae mobilizations & 1 & 0 & 0 & 3 & 4 \\
\hline Total & 31 & 44 & 25 & 22 & 122 \\
\hline
\end{tabular}

$V S D$, Ventricular septal defect; $n c V S D$, noncommitted ventricular septal defect $I V R$, intraventricular repair; $R V O T$, right ventricular outflow tract; $R E V$, réparation à l'étage ventriculaire; $A S O$, arterial switch operation; $A V$, atrioventricular; $A P V R$, abnormal pulmonary venous return.

early mortality with a sensitivity of $80 \%$ and a specificity of $68 \%$.

Early reoperation. Early cardiac reoperation was needed in 26 patients $(6 \%)$ with no significant statistical differences between the anatomic types of DORV and the surgical strategies. The most frequent cause of early reoperation for subaortic VSD (Fallot type and VSD type) was residual $\operatorname{VSD}(35 \%, 9 / 26)$ (Table 5).

Late mortality. A total of 20 patients died, $16(80 \%)$ within the first year after repair. Causes of death were end-stage heart failure in 8 patients, complications of a mechanical valve in 3 patients, sudden death in 3 patients, death after reoperation in 2 patients ( 1 valve replacement after endocarditis, 1 RVOT enlargement), noncardiac death in 2 patients, and 1 missing information. No significant difference in late mortality was found between the anatomic types or the surgical strategies. Factors associated with late mortality for each surgical strategy in univariate analysis are shown in Table E2. In multivariate analysis, risk factors for late mortality were IVR: mitral valve abnormality $(P=.01)$ and concomitant procedure $(P<.01)$; IVR-RVOT reconstruction: subaortic obstruction $(P=.02)$; and IVR-ASO: concomitant procedure $(P<.01)$.

In the overall analysis, the factors associated with late mortality in univariate analysis are shown in Table E3. To determine the anatomic characteristics that affected late mortality, we performed a multivariate backward analysis (Table E4) including restrictive VSD, mitral cleft, and coronary artery anomalies. Risk factors for late mortality were restrictive VSD $(\mathrm{OR}, 2.7 ; 95 \% \mathrm{CI}, 1.2-6.3 ; P=.01)$, 

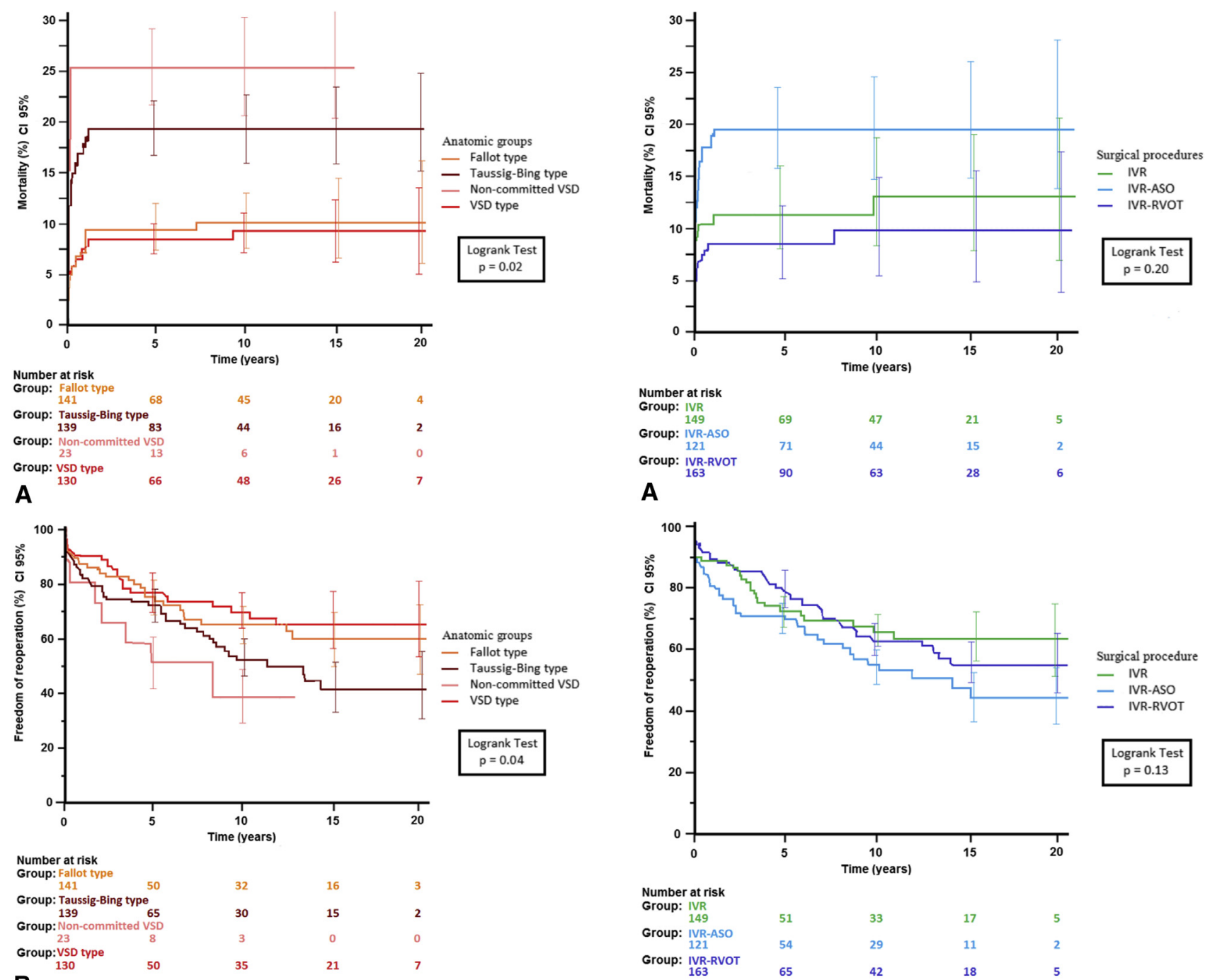

A
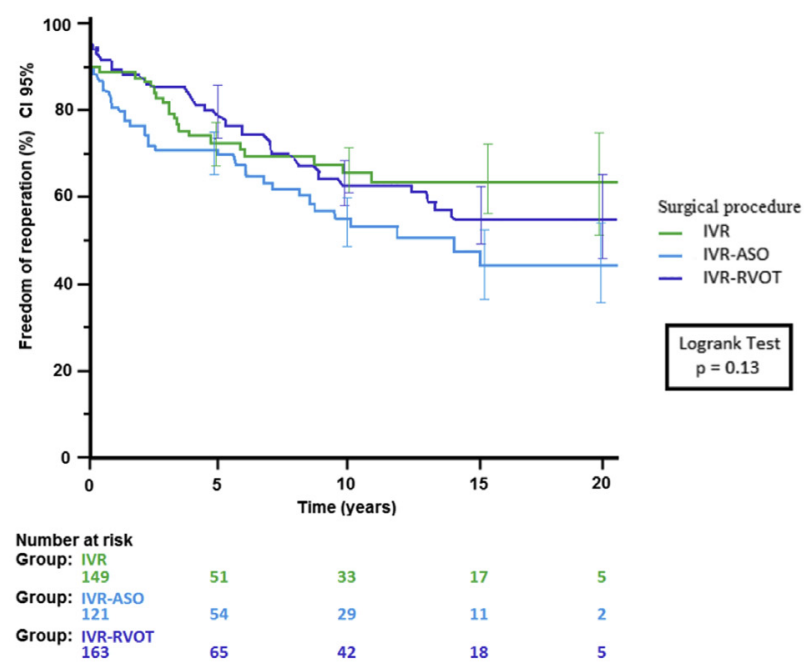

B

FIGURE 1. Outcomes according to anatomic type of DORV. A, Survival according to anatomic type of DORV. B, Freedom from reoperation according to anatomic type of DORV. CI, Confidence interval; VSD, ventricular septal defect.

mitral cleft (OR, 3.5; 95\% CI, 1.6-5.6; $P<.01)$, and coronary artery anomalies (OR, 2.9; 95\% CI, 1.5-3.9; $P=.01)$.

Late reoperation. A total of 97 patients underwent 136 reoperations at a median of 3.1 years after repair $(95 \%$ CI, 0.1-13) (Tables 6 and 7). A total of 71 patients underwent only 1 reoperation, 16 patients underwent 2 reoperations, 8 patients underwent 3 reoperations, 1 patient underwent 4 reoperations, and 1 patient underwent 5 reoperations. Freedom from reoperation was not different according to anatomic group or surgical strategy. Factors associated with late reoperation for each surgical strategy in univariate analysis are shown in Table E5. In multivariate analysis, risk factors for late reoperation were IVR: restrictive $\operatorname{VSD}(P=.04)$ and subaortic obstruction $(P=.04)$; IVR-RVOT reconstruction: duration of $\mathrm{CPB}$

FIGURE 2. Outcomes according to surgical strategy. A, Survival according to surgical strategy. B, Freedom from reoperation according to surgical strategy. $C I$, Confidence interval; $I V R$, intraventricular baffle repair; $A S O$, arterial switch operation; RVOT, right ventricular outflow tract.

$(P<.01)$; and IVR-ASO: subaortic obstruction $(P=.03)$, concomitant procedure $(P<.01)$, and days of intubation $(P<.01)$.

In the overall analysis, risk factors associated with reoperation in univariate analysis are shown in Table E3. In multivariate analysis (Table E4), including IPCC classification, surgical strategy, concomitant surgical procedure, and duration of $\mathrm{CPB}$, concomitant surgical procedure $(\mathrm{OR}, 1.6 ; 95 \% \mathrm{CI}, 1-2.5 ; P=.03)$ and duration of CPB (OR, 1.004; 95\% CI, 1.004-1.009; $P<.01$ ) were the 2 factors associated with late reoperations.

\section{DISCUSSION}

We report a large series of patients with DORV who underwent biventricular repair over a period of 21 years 
TABLE 4. Early surgical and postoperative characteristics ( $<30$ days) according to surgical strategies

\begin{tabular}{|c|c|c|c|c|}
\hline & $\operatorname{IVR}(n=149)$ & IVR-RVOT reconstruction $(n=163)$ & IVR-ASO $(n=121)$ & $P$ value \\
\hline \multicolumn{5}{|l|}{ Surgery } \\
\hline Age at repair $(\mathrm{d}$, median $[95 \% \mathrm{CI}])$ & 147 [121-235] & $423[318-597]$ & $26[18-57]^{*}$ & $<.01$ \\
\hline Weight $(\mathrm{kg}$, median $[95 \% \mathrm{CI}])$ & $5.2[4.6-6.0]$ & $7.9[7.0-8.6]$ & $3.4[3.3-3.5]^{*}$ & .02 \\
\hline Duration of CPB (min, mean) & 117 & 140 & 198 & .63 \\
\hline Aortic clamping time (min, mean) & 71 & 81 & 121 & .41 \\
\hline Concomitant procedures & 42 & 34 & 39 & .29 \\
\hline \multicolumn{5}{|l|}{ Postoperative characteristics } \\
\hline Inotropic support (d, median [95\% CI]) & $3[2-4]$ & $3[2-5]$ & $7[6-9]^{*}$ & .01 \\
\hline Duration of intubation $(\mathrm{d}$, median $[95 \% \mathrm{CI}])$ & $4[3-5]$ & $4[3-5]$ & $8[7-10]^{*}$ & .03 \\
\hline$\%$ Reoperation $(<30 \mathrm{~d})$ & $4.7 \%$ & $5.5 \%$ & $8.3 \%$ & .09 \\
\hline$\%$ Mortality $(<30 \mathrm{~d})$ & $7 \%$ & $4.3 \%$ & $10.7 \%$ * & .01 \\
\hline
\end{tabular}

in 2 surgical centers. The early mortality rate was $7.4 \%$, and 10 -year overall mortality rate was $13.8 \%$. The reoperation rate was $6 \%$ for early reoperation, and 10 -year overall reoperation rate was $38.6 \%$. Anatomic type of DORV influenced the outcomes, because ncVSD was associated with a higher risk of death and reoperation compared with the other groups. Mortality was higher in the TaussigBing type than in the VSD type. These differences may be related to the fact that the anatomic type of DORV is the main determinant of the surgical strategy. However, late survival and freedom from reoperation were not different for the 3 surgical cohorts.

$\mathrm{Li}$ and colleagues ${ }^{8}$ recently reported a similar series with a shorter follow-up, with early death in $4.4 \%$. The contemporary character of the study and lower proportion of Taussig-Bing type $(20 \%)$ in their series may explain the difference with the present report. Kleinert and colleagues ${ }^{5}$ reported early death in $8 \%(12 / 148$ DORV with biventricular repair) with a proportion of anatomic subtypes identical to our series.

\section{Outcomes According to Anatomic Characteristics}

The proportion of the different types of DORV in our series is similar to the majority of previously reported

TABLE 5. Indications for early reoperation according to anatomic group

\begin{tabular}{|c|c|c|c|c|c|}
\hline Indication & $\begin{array}{l}\text { Fallot } \\
\text { type }\end{array}$ & $\begin{array}{l}\text { VSD } \\
\text { type }\end{array}$ & $\begin{array}{l}\text { Taussig- } \\
\text { Bing type }\end{array}$ & ncVSD & Total \\
\hline Residual VSD & 4 & 3 & 1 & 1 & 9 \\
\hline RVOT reconstruction & 4 & & 4 & & 8 \\
\hline $\begin{array}{l}\text { Coronary artery } \\
\text { complications }\end{array}$ & 1 & & 3 & & 4 \\
\hline Subaortic obstruction & & 1 & 2 & & 3 \\
\hline Banding of PA & & 1 & & & 1 \\
\hline \multirow{2}{*}{$\begin{array}{l}\text { Mechanical valve } \\
\text { thrombosis }\end{array}$} & & & 1 & & 1 \\
\hline & 9 & 5 & 11 & 1 & 26 \\
\hline
\end{tabular}

$V S D$, Ventricular septal defect; $n c V S D$, noncommitted ventricular septal defect; $R V O T$, right ventricular outflow tract; $P A$, pulmonary artery. series, ${ }^{5,6}$ with $60 \%$ of subaortic (or doubly committed) VSD, $30 \%$ to $35 \%$ of subpulmonary VSD ${ }^{13}$ (ie, TaussigBing heart), and $5 \%$ to $10 \%$ of ncVSD. ${ }^{14}$

We observed that DORV with ncVSD was the only anatomic subgroup in which early and late mortality rates were significantly higher compared with other anatomic groups. Belli and colleagues ${ }^{14}$ and Lacour-Gayet et $\mathrm{al}^{15}$ showed the same trends in their series of DORV with ncVSD. Although Brown and colleagues ${ }^{16}$ reported biventricular repair in a high proportion of DORV with ncVSD, the choice of this approach as opposed to a univentricular palliation program should be carefully analyzed, because the risk of death and reoperation remains high. The distance between the VSD and the great arteries ${ }^{14}$ the location of the VSD (inlet, muscular, or central perimembranous), ${ }^{12}$ and the evaluation of the outflow tracts, AV valves, and global anatomy are the main parameters that should be analyzed to indicate a biventricular repair or a univentricular strategy in DORV with ncVSD. Redirecting the ncVSD to the unobstructed RVOT associated with the ASO procedure, performed in 5 cases in our series, appeared to be a valuable alternative in this unfavorable anatomic subset.

Acquired RVOT obstruction was the main cause of reoperation in the Taussig-Bing type compared with the VSD type. Hayes and colleagues ${ }^{13}$ reported that it was the main cause of reoperation $(5 / 11,45 \%)$ in a series of 43 Taussig-Bing anomalies. In the series by Kleinert and colleagues, ${ }^{5}$ hemodynamically significant subaortic obstruction (valvar or subvalvar aortic stenosis) and anatomic substrate for subaortic obstruction (expressing itself as coarctation of the aorta or interrupted aortic arch) were the only anatomic factors, with VSD location associated with early mortality.

The anatomic factors associated with late mortality (except ncVSD) were restrictive VSD, mitral cleft, and coronary artery anomalies. Restrictive VSD is a major anatomic parameter that influences preoperative clinical tolerance, timing of surgical intervention, duration of procedure, and intracardiac tunnel geometry. The enlargement of 
TABLE 6. Indications for late reoperation according to anatomic group

\begin{tabular}{lccccr}
\hline \multicolumn{1}{c}{ Indication } & $\begin{array}{c}\text { Fallot } \\
\text { type }\end{array}$ & $\begin{array}{c}\text { VSD } \\
\text { type }\end{array}$ & $\begin{array}{c}\text { Taussig- } \\
\text { Bing type }\end{array}$ & ncVSD & Total \\
\hline Subaortic obstruction & 8 & 15 & 7 & 5 & 35 \\
Aortic valve repair & 1 & 2 & 10 & & 13 \\
Aortic arch repair & & & 11 & & 11 \\
RVOT reconstruction & 13 & 7 & 15 & 3 & 38 \\
Pulmonary artery & 5 & & 1 & & 6 \\
$\quad$ branch repair & & & & & \\
Residual VSD closure & 4 & 6 & 4 & & 14 \\
AV valve repair & 2 & & 1 & 2 & 5 \\
Pacemaker implantation & 4 & 3 & 2 & 1 & 10 \\
Endocarditis & & 1 & 1 & & 2 \\
ASD closure & & & 1 & & 1 \\
Heart transplantation & & & 1 & & 1 \\
& 37 & 34 & 54 & 11 & 136 \\
\hline
\end{tabular}

$V S D$, Ventricular septal defect; $n c V S D$, noncommitted ventricular septal defect; $R V O T$, right ventricular outflow tract; $A V$, atrioventricular; $A S D$, atrial septal defect.

VSD, which was indicated in front of a diagnostic of restrictive VSD during the preoperative evaluation or the surgical procedure (when the surgeon deemed it necessary to intraventricular baffle), was the most frequent additional procedure $(23 / 45,51 \%)$. In the series by $\mathrm{Li}$ and colleagues, ${ }^{8}$ the most frequent additional procedure $(23 / 45,51 \%)$ was the enlargement of the VSD, which was indicated when restrictive VSD was diagnosed during the preoperative evaluation or during the surgical procedure (when the surgeon considered it necessary). This was performed in only 35 of 122 patients $(29 \%)$ in our series. Nevertheless, the IVR, with or without enlargement of VSD, carries a high risk for reoperation for VSD residual (or modification of baffle repair) ahead of DORVs or all types of conotruncal abnormalities. ${ }^{17}$ We believe this surgical parameter requires a particularly precise surgical management (size and localization of septal resection) to avoid risks in the short

TABLE 7. Indications for late reoperation and surgical strategy

\begin{tabular}{lrccr}
\hline \multicolumn{1}{c}{ Indication } & IVR & IVR-RVOT & IVR-ASO & Total \\
\hline Subaortic obstruction & 17 & 9 & 9 & 35 \\
Aortic valve repair & 2 & 1 & 10 & 13 \\
Aortic arch repair & & & 11 & 11 \\
RVOT reconstruction & 5 & 24 & 9 & 38 \\
Pulmonary artery branch repair & 1 & 4 & 1 & 6 \\
Residual VSD closure & 5 & 3 & 6 & 14 \\
AV valve repair & 3 & 1 & 1 & 5 \\
Pacemaker implantation & 3 & 4 & 3 & 10 \\
Endocarditis & 1 & & 1 & 2 \\
ASD closure & & & 1 & 1 \\
Heart transplantation & & 1 & & 1 \\
& 37 & 47 & 51 & 136 \\
\hline
\end{tabular}

$I V R$, Intraventricular repair; RVOT, right ventricular outflow tract; $A S O$, arterial switch operation; $V S D$, ventricular septal defect; $A V$, atrioventricular; $A S D$, atrial septal defect. term (conduction disorders, residual VSD) and long term (subaortic obstruction). In regard to reoperation for left ventricular outflow obstruction, one may conclude that an aggressive approach with almost routine VSD enlargement may decrease late left ventricular outflow obstruction. Nevertheless, because it was difficult for us to demonstrate this approach statistically, we have to consider these conclusions and suggestions cautiously. A prospective study would be appropriate to investigate this.

\section{Outcomes According to Surgical Strategy}

IVR-ASO was the surgical strategy that carried the highest risk of early mortality independently of the anatomic subtype of DORV. Of note, IVR-ASO was performed primarily in infants with lower weight and who required higher duration of CPB (Table 4). These factors are known to be risk factors for early mortality after surgery for congenital heart diseases. ${ }^{18,19}$ The early mortality for IVR-ASO was higher than after the arterial switch for transposition of the great arteries $(10.7 \%$ vs $6 \%){ }^{20}$ The need to build an intracardiac baffle from the VSD to the neoaorta, the higher incidence of abnormal coronary artery origin/course, and the frequent association of aortic arch obstruction, resulting in a longer procedure, may explain this trend. ${ }^{21}$

In this study, we could not demonstrate any differences in late mortality according to the initial strategy. The small number of deaths in the first year postsurgery $(4 / 433,1 \%)$ certainly limits this conclusion. Li and colleagues ${ }^{8}$ reported no death after the first year, but their follow-up was shorter ( $3.4 \pm 3.9$ years). Belli and colleagues ${ }^{6}$ reported 2 deaths $(2 / 151,1 \%)$ in their series, with a follow-up of 4.3 years. Late mortality is low after biventricular repair in DORV, and adverse events are mainly reoperations. Indeed, approximately one third of the patients in our series had to undergo a reoperation (Table 7). Some $43 \%$ of these reoperations were related to left heart residual or acquired anomalies. The types of left heart anomalies observed were different according to the initial surgical strategy. Subaortic obstruction related to baffle stenosis was the main cause of reoperations in the IVR and IVR-RVOT groups ( $90 \%$ of indications), whereas it occurred in only one third of patients undergoing reoperation after IVR-ASO. Conversely, aortic arch repair or ascending aorta and aortic valve repair were frequent in the IVR-ASO group and rare in the 2 other surgical strategies. These results are similar to those of Losay and colleagues, ${ }^{22}$ who reported that aortic arch reconstruction $(15 / 39,38 \%)$ and aortic valve repair $(13 / 39,33 \%)$ were the major indications of late reoperation for left heart anomalies in a large series of 1200 transpositions of the great arteries after ASO. Belli and colleagues ${ }^{23}$ also showed that subaortic valve obstruction developed with time and was the main cause of reoperation $(73 \%)$ after IVR or IVR-RVOT. Of note, abnormal coronary artery 
distribution was a risk factor for late mortality in multivariate analysis. We were not able to demonstrate that this was related only to the IVR-ASO procedure.

Reoperations involving the right heart obviously were more frequent in patients who had a RVOT reconstruction at initial repair. In this IVR-RVOT group, 60\% (28/47) of late reoperations were related to RVOT anomalies with half of reoperations related to replacement of a conduit. ${ }^{24}$ Residual VSD closure was required in $10 \%$ of the cases with no difference in the 3 strategies.

The initial strategy is determined by the underlying anatomy of the DORV. The VSD location is the major determinant to choose between the available options. Decisional algorithms have been designed to choose the optimal surgical procedure according to different anatomic factors. ${ }^{8}$ When the initial repair is performed, late outcomes are similar in the different anatomic subtypes of DORV. This is certainly reassuring for the counseling of families, particularly when a prenatal diagnosis of DORV has been made.

\section{Study Limitations}

The main limitation of this study is in the anatomic classification of DORV, which is insufficiently complete to allow the anatomic groups to coincide with surgical strategies. The relationship of the VSD to the great arteries and the presence or absence of subpulmonary obstruction are necessary but not sufficient elements to decide on the proper surgical strategy for a DORV. This is the reason why various surgical strategies are presented for each anatomic group in our study.

Our surgical classification for 3 main groups has forced us to assemble different strategies for IVR-RVOT enlargement, such as the Lecompte or Rastelli procedures. We were unable to analyze separately the different substrategies in the IVR-RVOT group. For patients with the TaussigBing type undergoing a Lecompte or Rastelli procedure, we classified them in the IVR-RVOT surgical group because the aorta was not mobilized during surgery (no arterial switch by definition). That is why in our series the Taussig-Bing type does not automatically imply a classification for the IVR-ASO strategy. Risk factor analysis is by nature a predictor of outcome, which may, in turn, be influenced by varying treatment options.

\section{CONCLUSIONS}

DORV is a complex and heterogeneous anatomic group of congenital heart anomalies. Despite constant improvements in outcomes, mortality and need for reoperation remain significant because of the clinical challenge imposed by the "most complex" anatomic forms. The ncVSD type carries a higher risk of events compared with the other anatomic types of DORV, and the biventricular (vs univentricular) strategy in this setting needs to be evaluated by specific studies. The IVR-ASO group requiring a neonatal procedure has the highest risk of early death. One third of the patients had to undergo reoperation, and the type of reoperation depends on the initial repair. The absence of difference in late mortality or reoperation among the 3 surgical strategies is certainly an important element, particularly for prenatal counseling.

\section{Conflict of Interest Statement}

Authors have nothing to disclose with regard to commercial support.

\section{References}

1. Walters HL, Mavroudis C, Tchervenkov C, Jacobs JP, Lacour-Gayet F, Jacobs ML. Congenital Heart Surgery Nomenclature and Database Project: double outlet right ventricle. Ann Thorac Surg. 2000;69:249-63.

2. European Association for Cardio-Thoracic Surgery, Society of Thoracic Surgeons, List S. European Paediatric Cardiac Code (IPCCC Short List). April 1, 2012. 2012:1-14. Available at: http://ipccc.net/index.php/download-theipccc/. Accessed June 13, 2016

3. Kirklin JK, Harp RA, Mcgoon DC. Surgical treatment of origin of both vessels from right ventricle, including cases of pulmonary stenosis. J Thorac Cardiovasc Surg. 1964;48:1026-36.

4. Lecompte Y, Batisse A, Di Carlo D. Double-outlet right ventricle: a surgical synthesis. Adv Card Surg. 1993;4:109-36.

5. Kleinert S, Sano T, Weintraub RG, Mee RB, Karl TR, Wilkinson JL. Anatomic features and surgical strategies in double-outlet right ventricle. Circulation. 1997;96:1233-9

6. Belli E, Serraf A, Lacour-Gayet F, Prodan S, Piot D, Losay J, et al. Biventricular repair for double-outlet right ventricle. Results and long-term follow-up. Circulation. 1998;98(19 Suppl):II360-7.

7. Artrip JH, Sauer H, Campbell DN, Mitchell MB, Haun C, Almodovar MC, et al Biventricular repair in double outlet right ventricle: surgical results based on the STS-EACTS International Nomenclature classification. Eur J Cardiothorac Surg. 2006;29:545-50.

8. Li S, Ma K, Hu S, Hua Z, Yang K, Yan J, et al. Surgical outcomes of 380 patients with double outlet right ventricle who underwent biventricular repair. $J$ Thorac Cardiovasc Surg. 2014;148:817-24.

9. Tchervenkov C, Walters HL, Chu VF. Congenital Heart Surgery Nomenclature and Database Project: double outlet left ventricle. Ann Thorac Surg. 2000;69(4 Suppl):S264-9.

10. Van Praagh R. What is the Taussig-Bing malformation? Circulation. 1968;38: 445-9.

11. Lev M, Bharati S, Meng CC, Liberthson RR, Paul MH, Idriss F A concept of double-outlet right ventricle. J Thorac Cardiovasc Surg. 1972 64:271-81.

12. Mostefa-Kara M, Bonnet D, Belli E, Fadel E, Houyel L. Anatomy of the ventricular septal defect in outflow tract defects: similarities and differences. J Thorac Cardiovasc Surg. 2014;149:682-8.

13. Hayes DA, Jones S, Quaegebeur JM, Richmond ME, Andrews HF, Glickstein JS, et al. Primary arterial switch operation as a strategy for total correction of Taussig-Bing anomaly: a 21-year experience. Circulation. 2013;128(11 Suppl 1):S194-8.

14. Belli E, Serraf A, Lacour-Gayet F, Hubler M, Zoghby J, Houyel L, et al Double-outlet right ventricle with non-committed ventricular septal defect. Eur J Cardiothoracic Surg. 1999;15:747-52.

15. Lacour-Gayet F, Haun C, Ntalakoura K, Belli E, Houyel L, Marcsek P, et al. Biventricular repair of double outlet right ventricle with non-committed ventricular septal defect (VSD) by VSD rerouting to the pulmonary artery and arterial switch. Eur J Cardiothoracic Surg. 2002;21:1042-8.

16. Brown JW, Ruzmetov M, Okada Y, Vijay P, Turrentine MW. Surgical results in patients with double outlet right ventricle: a 20-year experience. Ann Thorac Surg. 2001;72:1630-5.

17. Patel JK, Glatz AC, Ghosh RM, Jones SM, Natarajan S, Ravishankar C, et al Intramural ventricular septal defect is a distinct clinical entity associated with postoperative morbidity in children after repair of conotruncal anomalies. Circulation. 2015;132:1387-94. 
18. Curzon CL, Milford-Beland S, Li JS, O'Brien SM, Jacobs JP, Jacobs ML. Cardiac surgery in infants with low birth weight is associated with increased mortality: analysis of the Society of Thoracic Surgeons Congenital Heart Database. J Thorac Cardiovasc Surg. 2008;135:546-51.

19. Jenkins KJ, Newburger JW, Lock JE, Davis RB, Coffman GA, Lezzoni LI. In-hospital mortality for surgical repair of congenital heart defects: preliminary observations of variation by hospital caseload. Pediatrics. 1995;95:323-30.

20. Prêtre R, Tamisier D, Bonhoeffer P, Mauriat P, Pouard P, Sidi D. Results of the arterial switch operation in neonates with transposed great arteries. Lancet. 2001:357:1826-30.

21. Vergnat M, Baruteau AE, Houyel L, Ly M, Roussin R, Capderou A, et al. Late outcomes after arterial switch operation for Taussig-Bing anomaly. J Thorac Cardiovasc Surg. 2015;149:1124-30.
22. Losay J, Touchot A, Serraf A, Litvinova A, Lambert V, Piot JD, et al. Late outcome after arterial switch operation for transposition of the great arteries. Circulation. 2001;104(Suppl 1):I-121-6.

23. Belli E, Serraf A, Lacour-Gayet F, Inamo J, Houyel L, Bruniaux J, et al. Surgical treatment of subaortic stenosis after biventricular repair of double-outlet right ventricle. J Thorac Cardiovasc Surg. 1996;112:1570-80.

24. Kreutzer C, De Vive J, Oppido G, Kreutzer J, Gauvreau K, Freed M, et al. Twenty-five-year experience with Rastelli repair for transposition of the great arteries. J Thorac Cardiovasc Surg. 2000;120:211-23.

Key Words: congenital heart disease, double-outlet right ventricle, outcome, pediatrics, surgery

Readers who found these articles interesting may also like to read the following papers found in recent and future issues of our sister publications, Seminars in Thoracic and Cardiovascular Surgery and Operative Techniques in Thoracic and Cardiovascular Surgery!

\section{Congenital}

State of the Art: Interrupted Aortic Arch. Richard Jonas. Semin Thorac Cardiovasc Surg 2015; Summer; 27(2):177-188.

Original Submission: Should Tricuspid annuloplasty be performed with pulmonary valve replacement for pulmonary regurgitation in repaired tetralogy of fallot? Pranava Sinha. Semin Thorac Cardiovasc Surg 2015; Summer; 27(2): 159-165.

Editorial Commentary: PI Leads to RVE, Which Leads to TR, Which Leads to More RVE, Which Leads to More TR: A Vicious Cycle? Charles B. Huddleston. Semin Thorac Cardiovasc Surg 2015; Summer; 27(2): 166-167.

Original Submission: Unsatisfactory early and late outcomes after Fontan surgery delayed to adolescence and adulthood. Yves D'Udekem. Semin Thorac Cardiovasc Surg 2015; Summer; 27(2):168-174.

Editorial Commentary: The Fontan Operation: Is Timing Everything? Harold M. Burkhart. Semin Thorac Cardiovasc Surg 2015; Summer; 27(2): 175.

Discussions in Cardiothoracic Treatment and Care: Tetralogy of Fallot. Charles Fraser. Semin Thorac Cardiovasc Surg 2015; Summer; 27(2):189-204.

Original Submission: Preliminary experience in the use of an extracellular matrix (CorMatrix) as a tube graft: Word of caution. Narutoshi Hibino. Semin Thorac Cardiovasc Surg 2015; Autumn; 27(3):288-295.

Original Submission: Efficacy of artificial chordal reconstruction for idiopathic severe mittral regurgitation due to chordal rupture in infancy. Sadahiro Sai. Semin Thorac Cardiovasc Surg 2015; Autumn; 27(3):321-325.

Original Submission: The mid-term outcomes of bioprosthetic pulmonary valve replacement in children. Takeshi Shinkawa. Semin Thorac Cardiovasc Surg 2015; Autumn; 27(3):310-318.

Original Submission: Health-related quality of life in adult survivors after the Fontan operation. James Kirklin. Semin Thorac Cardiovasc Surg 2015; Autumn; 27(3):307-308.

Repair of Atrioventricular Septal Defects: The 2-Patch Sandwich Technique. Hagi Dekel. Oper Tech Thorac Cardiovasc Surg 2015; Spring; 20(1):63-74.

Classic Single-Patch Repair of Atrioventricular Septal Defects. Anees J. Razzouk. Oper Tech Thorac Cardiovasc Surg 2015; Spring; 20(1):75-86.

Microvascular Coronary Artery Repair and Grafting in Infancy and Early Childhood. Joseph Catapano. Oper Tech Thorac Cardiovasc Surg 2015; Summer; 20(2):148-161.

Repair of Anomalous Coronary Artery from the Pulmonary Artery by Aortic Implantation. Anthony Azakie. Oper Tech Thorac Cardiovasc Surg 2015; Summer; 20(2):135-147.

No ventricular septal defect patch atrioventricular septal defect repair. Carl Backer. Oper Tech Thorac Cardiovasc Surg 2015; Autumn; 20(3):279-292.

Potts shunt for children with severe pulmonary hypertension. Pirooz Eghtesady. Oper Tech Thorac Cardiovasc Surg 2015; Autumn; 20(3):293-305. 
TABLE E1. List of variables considered for multivariable analyses in overall analysis

\begin{tabular}{ll}
\hline \multicolumn{1}{c}{ Late reoperation } & \multicolumn{1}{c}{ Late mortality } \\
\hline Restrictive VSD & Restrictive VSD \\
Subaortic obstruction & Mitral cleft \\
Concomitant surgical procedure & Coronary artery anomalies \\
Duration of CPB & \\
Days of intubation & \\
\hline$V S D$, Ventricular septal defect; $C P B$, cardiopulmonary bypass.
\end{tabular}

TABLE E2. Univariate analysis for late mortality

\begin{tabular}{|c|c|c|c|c|c|c|}
\hline & \multicolumn{6}{|c|}{ Mortality } \\
\hline & \multicolumn{2}{|c|}{ IVR $(n=149)$} & \multicolumn{2}{|c|}{ IVR-RVOT $(\mathrm{n}=163)$} & \multicolumn{2}{|c|}{ IVR-ASO $(n=121)$} \\
\hline & $\mathbf{9 5} \% \mathrm{CI}$ & $P$ & $\mathbf{9 5} \% \mathrm{CI}$ & $P$ & $95 \% \mathrm{CI}$ & $P$ \\
\hline \multicolumn{7}{|l|}{ Demographic } \\
\hline Gender & $0.4-2.8$ & .98 & $0.1-1.3$ & .12 & $0.4-1.9$ & .69 \\
\hline Center & $0.5-3.8$ & .53 & $0.2-2.3$ & .63 & $0.9-4.6$ & .08 \\
\hline Postnatal diagnosis & $0.3-2.6$ & .90 & $0.1-1.2$ & .10 & $0.4-2.1$ & .88 \\
\hline Genetic abnormality & $0.2-4.5$ & .64 & $0.4-2.9$ & .35 & $0.6-5.7$ & .74 \\
\hline \multicolumn{7}{|l|}{ Anatomy } \\
\hline Fallot type & $0.5-1.6$ & .54 & $0.3-1.4$ & .64 & NA & NA \\
\hline VSD type & $0.3-1.8$ & .78 & $0.1-21$ & .96 & NA & NA \\
\hline Taussig-Bing type & NA & NA & $0.2-5.2$ & .89 & $0.5-1.8$ & .31 \\
\hline ncVSD & $1.2-2.2$ & .04 & $0.6-14$ & .16 & $1.3-2.7$ & .03 \\
\hline Multiple VSD & $0.4-2.3$ & .36 & $0.1-6.9$ & .91 & $0.7-4.6$ & .18 \\
\hline Restrictive VSD & $0.4-20$ & .06 & $0.4-9.1$ & .36 & $0.7-7.9$ & .16 \\
\hline Subpulmonary obstruction & NA & NA & $0.3-2.1$ & .15 & $0.3-2.7$ & .83 \\
\hline Subaortic obstruction* & $0.7-7.6$ & .09 & $2.2-15$ & $<.01$ & $0.7-3.6$ & .23 \\
\hline AVSD & 2.4-89 & $<.01$ & $0.1-94$ & .49 & $0.1-67$ & .30 \\
\hline Mitral cleft & 1.3-2.1 & .04 & $0.4-23$ & .29 & $1.2-31$ & .03 \\
\hline Straddling & $0.1-4.3$ & .59 & $0.1-8.6$ & .91 & $0.5-2.5$ & .84 \\
\hline Mitral valve abnormality & 1.3-11 & $<.01$ & $0.7-15$ & .11 & $0.9-7.9$ & .06 \\
\hline Coronary artery anomalies & $1.2-5.9$ & .04 & $0.9-2.6$ & .07 & $0.9-4.4$ & .15 \\
\hline \multicolumn{7}{|l|}{ Previous palliative surgery } \\
\hline Palliative procedure & $0.3-2.8$ & .88 & $0.8-8.6$ & .12 & $0.4-2.6$ & .95 \\
\hline \multicolumn{7}{|l|}{ Surgical strategy } \\
\hline Date $(>/<2002)$ & $0.2-5.4$ & .34 & $0.3-2.1$ & .69 & $0.7-2.9$ & .24 \\
\hline Age & $0.9-1.0$ & .78 & $0.9-1.0$ & .34 & $0.9-1.0$ & .23 \\
\hline Weight & $1.0-1.1$ & .03 & $0.9-1.0$ & .056 & $0.9-1.0$ & .01 \\
\hline Concomitant procedure & $2.2-18$ & $<.01$ & $0.2-3.5$ & .75 & $1.7-25$ & $<.01$ \\
\hline Duration of $\mathrm{CPB}$ & $0.9-1.3$ & .11 & 1.0-1.1 & $<.01$ & 1.0-1.1 & $<.01$ \\
\hline \multicolumn{7}{|l|}{ Postsurgery } \\
\hline Days of intubation & $0.7-1.4$ & .88 & $1.1-1.2$ & .02 & 1.0-1.1 & $<.01$ \\
\hline Early reoperation $(<30 \mathrm{~d})$ & $0.2-13$ & .61 & $1.9-26$ & $<.01$ & $2.2-14$ & $<.01$ \\
\hline Late reoperation $(>30 \mathrm{~d})$ & $0.9-83$ & .06 & $0.3-9.3$ & .61 & $0.1-1.5$ & .12 \\
\hline No. of reoperations $>1$ & $0.5-7.1$ & .41 & $0.7-13$ & .12 & $0.5-48$ & .40 \\
\hline
\end{tabular}


TABLE E3. Univariate analysis of overall cohort for late outcomes

\begin{tabular}{|c|c|c|c|c|c|c|}
\hline & \multicolumn{3}{|c|}{ Reoperation } & \multicolumn{3}{|c|}{ Mortality } \\
\hline & HR & $95 \% \mathrm{CI}$ & $\boldsymbol{P}$ & HR & $95 \% \mathrm{CI}$ & $\boldsymbol{P}$ \\
\hline \multicolumn{7}{|l|}{ Demographic } \\
\hline Gender & 1.16 & $0.80-1.68$ & .4 & 0.79 & $0.46-1.35$ & .4 \\
\hline Center & 0.92 & $0.53-1.60$ & 6 & 1.12 & $0.66-1.93$ & 6 \\
\hline Postnatal diagnosis & 0.96 & $0.66-1.41$ & .8 & 0.84 & $0.49-1.45$ & .5 \\
\hline Genetic abnormality & & & .8 & & & .8 \\
\hline \multicolumn{7}{|l|}{ Anatomy } \\
\hline Fallot type & 0.84 & $0.56-1.27$ & .4 & 0.65 & $0.34-1.23$ & .2 \\
\hline VSD type & 2.02 & $0.93-4.38$ & .1 & 0.88 & $0.38-2.04$ & .9 \\
\hline Taussig-Bing type & 1.37 & $0.88-2.14$ & .1 & 1.92 & $0.97-3.82$ & .06 \\
\hline $\mathrm{ncVSD}$ & 2.02 & $0.93-4.38$ & .08 & 2.99 & $1.06-8.46$ & .02 \\
\hline Multiple VSD & 0.86 & $0.46-1.59$ & .8 & .2711 & $0.57-2.81$ & .6 \\
\hline Restrictive VSD & 1.75 & $0.98-3.12$ & .06 & 2.29 & $1.08-4.84$ & .03 \\
\hline Subpulmonary obstruction & & & .3 & & & .3 \\
\hline Subaortic obstruction* & & & $<.01$ & & & $<.01$ \\
\hline AVSD & & & .1 & & & .06 \\
\hline Mitral cleft & 2.06 & $0.76-5.57$ & .1 & 3.30 & $1.70-6.4100$ & $<.01$ \\
\hline Straddling & 1.14 & $0.70-1.86$ & 6 & 1.28 & $0.64-2.53$ & .5 \\
\hline Mitral valve abnormality & 1.72 & $0.92-3.20$ & .08 & 1.45 & $0.71-2.19$ & .4 \\
\hline Coronary artery anomalies & 1.28 & $0.87-1.88$ & .2 & 1.93 & 1.11-3.35 & .01 \\
\hline \multicolumn{7}{|l|}{ Previous palliative surgery } \\
\hline Palliative procedure & 1.17 & $0.80-1.70$ & .4 & .042 & $0.59-1.86$ & .9 \\
\hline \multicolumn{7}{|l|}{ Surgical strategy } \\
\hline Date $(>/<2002)$ & 1.34 & $0.85-2.09$ & .8 & 1.42 & $0.73-2.29$ & .4 \\
\hline Age & 1.00 & $0.99-1.00$ & .1 & 0.99 & $0.99-1.00$ & .08 \\
\hline Weight & 1.00 & $0.99-1.00$ & .2 & 0.99 & $0.99-1.00$ & .03 \\
\hline IVR & 0.79 & $0.53-1.20$ & .3 & 0.82 & $0.45-1.48$ & .5 \\
\hline IVR-RVOT & 1.08 & $0.68-1.72$ & .7 & 0.70 & $0.33-1.50$ & .3 \\
\hline IVR-ASO & 1.49 & $0.94-2.36$ & .08 & 1.90 & 1.01-3.59 & .04 \\
\hline Concomitant procedure & 1.84 & $1.25-2.72$ & $<.01$ & 2.58 & $1.50-4.44$ & $<.01$ \\
\hline Duration of $\mathrm{CPB}$ & 1.01 & $1.00-1.01$ & $<.01$ & 1.01 & 1.01-1.02 & $<.01$ \\
\hline \multicolumn{7}{|l|}{ Postsurgery } \\
\hline Days of intubation & 1.05 & 1.04-1.07 & $<.01$ & 1.04 & 1.02-1.07 & $<.01$ \\
\hline Early reoperation $(<30 \mathrm{~d})$ & & NA & & 5.06 & 2.51-10.19 & $<.01$ \\
\hline Late reoperation $(>30 \mathrm{~d})$ & & NA & & 1.04 & $0.40-2.69$ & .9 \\
\hline No. of reoperations $>1$ & & NA & & 2.57 & $0.52-12.62$ & .2 \\
\hline
\end{tabular}

$H R$, Hazard ratio; $C I$, confidence interval; $V S D$, ventricular septal defect; $n c V S D$, noncommitted ventricular septal defect; $A V S D$, atrioventricular septal defect; $I V R$, intraventricular repair; RVOT, right ventricular outflow tract; $A S O$, arterial switch operation; $C P B$, cardiopulmonary bypass; $N A$, not applicable. *Subaortic obstruction (including the patients with coarctation of aorta, interrupted aortic arch, valvular, or subvalvular aortic stenosis). 
TABLE E4. Multivariate analysis results of overall cohort for late outcomes (with the number of events)

\begin{tabular}{|c|c|c|c|c|c|c|}
\hline \multicolumn{7}{|c|}{ Late mortality $(\mathrm{n}=\mathbf{2 0})$} \\
\hline Covariate (events) & b & SE & Wald & $\boldsymbol{P}$ & $\operatorname{Exp}(\mathbf{b})$ & $95 \%$ CI of $\operatorname{Exp}(b)$ \\
\hline Restrictive VSD $(\mathrm{n}=11)$ & 0.9619 & 0.4088 & 5.5367 & .0144 & 2.7113 & $1.2161-6.3494$ \\
\hline Mitral cleft $(\mathrm{n}=8)$ & 1.3328 & 0.3534 & 14,220 & .0037 & 3.5022 & $1.6193-5.5812$ \\
\hline Coronaries artery anomalies $(n=12)$ & 1.1243 & 0.6852 & 9.2564 & .0139 & 2.8831 & $1.5016-3.922$ \\
\hline \multicolumn{7}{|c|}{ Late reoperation $(n=97)$} \\
\hline Covariate & b & SE & Wald & $\boldsymbol{P}$ & $\operatorname{Exp}(\mathbf{b})$ & $95 \%$ CI of $\operatorname{Exp}(b)$ \\
\hline Concomitant surgical procedure $(\mathrm{n}=29)$ & 0.4917 & 0.2287 & 4.6246 & .0315 & 1.6351 & $1.0469-2.5539$ \\
\hline Duration of CPB & 0.0069 & 0.0014 & 24.459 & $<.001$ & 1.0070 & $1.0042-1.0097$ \\
\hline
\end{tabular}

$S E$, Standard error; $C I$, confidence interval; $V S D$, ventricular septal defect; $C P B$, cardiopulmonary bypass.

TABLE E5. Univariate analysis for late reoperation

\begin{tabular}{|c|c|c|c|c|c|c|}
\hline & \multicolumn{6}{|c|}{ Reoperation } \\
\hline & \multicolumn{2}{|c|}{ IVR $(n=149)$} & \multicolumn{2}{|c|}{ IVR-RVOT $(n=163)$} & \multicolumn{2}{|c|}{ IVR-ASO $(\mathbf{n}=121)$} \\
\hline & $95 \% \mathrm{CI}$ & $P$ & $95 \% \mathrm{CI}$ & $\boldsymbol{P}$ & $95 \% \mathrm{CI}$ & $P$ \\
\hline \multicolumn{7}{|l|}{ Demographic } \\
\hline Gender & $0.6-2.6$ & .55 & $0.5-1.9$ & .88 & $0.6-2.4$ & .48 \\
\hline Center & $0.3-1.2$ & .15 & $0.4-1.3$ & .17 & $0.6-2.3$ & .52 \\
\hline Postnatal diagnosis & $0.5-2.5$ & .73 & $0.4-1.4$ & .40 & $0.6-2.1$ & .73 \\
\hline Genetic abnormality & $0.4-1.6$ & .59 & $0.8-1.7$ & .24 & $0.7-1.6$ & .29 \\
\hline \multicolumn{7}{|l|}{ Anatomy } \\
\hline Fallot type & $0.6-2.1$ & .41 & $0.4-2.1$ & .62 & NA & NA \\
\hline VSD type & $0.2-1.8$ & .57 & $0.3-2.7$ & .88 & NA & NA \\
\hline Taussig-Bing type & NA & NA & $0.4-2.4$ & .90 & $0.7-2.4$ & .72 \\
\hline $\mathrm{ncVSD}$ & $0.4-11$ & .40 & $2.2-13$ & $<.01$ & $0.1-3.9$ & .54 \\
\hline Multiple VSD & $0.1-66$ & .97 & $0.3-2.3$ & .69 & $0.3-1.9$ & .65 \\
\hline Restrictive VSD & 0.1-0.9 & .04 & $0.5-3.3$ & .57 & 1.1-6.8 & .04 \\
\hline Subpulmonary obstruction & $0.8-1.9$ & .16 & $0.4-2$ & .83 & $0.8-2.4$ & .24 \\
\hline Subaortic obstruction* & $1.9-4.5$ & .02 & $0.3-1.9$ & .54 & 1.5-5.1 & $<.01$ \\
\hline AVSD & 2-7.1 & .01 & $0.1-17$ & .95 & $0.1-15$ & $<.01$ \\
\hline Mitral cleft & $0.4-5.9$ & .18 & $0.6-2.5$ & .16 & $0.9-1.9$ & .09 \\
\hline Straddling & $0.3-3.1$ & .94 & $0.4-2.6$ & .43 & $0.3-1.9$ & .67 \\
\hline Mitral valve abnormality & $0.2-4.3$ & .21 & $0.8-3.4$ & .11 & $0.8-4.7$ & .09 \\
\hline Coronary artery anomalies & $0.8-2.6$ & .10 & $0.2-1.7$ & .41 & $0.6-1.9$ & .30 \\
\hline \multicolumn{7}{|l|}{ Previous palliative surgery } \\
\hline Palliative procedure & $0.7-3.0$ & .30 & $0.6-2.2$ & .59 & $0.6-2.4$ & .64 \\
\hline \multicolumn{7}{|l|}{ Surgical strategy } \\
\hline Date $(>/<2002)$ & $0.6-1.8$ & .63 & $0.4-1.6$ & .91 & $0.8-2.2$ & .21 \\
\hline Age & $0.9-1.0$ & .59 & $0.9-1.0$ & .25 & $0.9-1.0$ & .36 \\
\hline Weight & $0.9-1.0$ & .86 & $0.9-1.0$ & .79 & $0.9-1.0$ & .40 \\
\hline Concomitant procedure & $0.8-4.1$ & .11 & $0.6-2.5$ & .65 & $1.2-4.1$ & $<.01$ \\
\hline Duration of CPB & $0.9-1.0$ & .052 & 1.0-1.1 & $<.01$ & 1-1.1 & $<.01$ \\
\hline \multicolumn{7}{|l|}{ Postsurgery } \\
\hline Days of intubation & $1-1.2$ & .04 & $1.0-1.1$ & $<.01$ & 1-1.1 & $<.01$ \\
\hline Early reoperation $(<30 \mathrm{~d})$ & \multicolumn{6}{|c|}{ NA } \\
\hline Late reoperation $(>30 \mathrm{~d})$ & \multicolumn{6}{|c|}{ NA } \\
\hline No. of reoperations $>1$ & \multicolumn{6}{|c|}{ NA } \\
\hline
\end{tabular}

